\title{
What to do with a pituitary incidentaloma?
}

Expert Rev. Endocrinol. Metab. 6(4), 505-507 (2011)

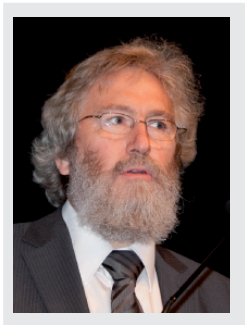

Albert Beckers

Author for correspondence Department of

Endocrinology, Centre Hospitalier Universitaire de Liège, Domaine Universitaire du Sart Tilman, University of Liège, 4000 Liège, Belgium Tel.: +3243668226 albert.beckers@chu.ulg.ac.be

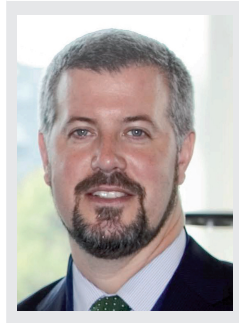

\section{Adrian F Daly}

Department of Endocrinology, Centre Hospitalier Universitaire de Liège, Domaine Universitaire du Sart Tilman, University of Liège, 4000 Liège, Belgium

\section{EXPERT
REVIEWS}

\author{
"The frequency with which pituitary adenomas occur is a topic \\ that has challenged endocrinologists for decades. From a \\ research perspective, pituitary adenomas, irrespective of size or \\ symptoms, are not unusual; indeed, they are very common."
}

A pituitary incidentaloma is a previously unsuspected pituitary lesion that is discovered on an imaging study performed for an unrelated reason [1].

The frequency with which pituitary adenomas occur is a topic that has challenged endocrinologists for decades. From a research perspective, pituitary adenomas, irrespective of size or symptoms, are not unusual; indeed, they are very common. As early as 1936, Russell Costello at the Mayo Clinic (Rochester, MN, USA) published a remarkable study of the pituitary glands of 1000 consecutive autopsy cases who had died of causes unrelated to pituitary disease [2]. Costello found that $22.5 \%$ of pituitaries contained at least one adenoma and, while the adenoma size was not reported, some were large enough to occupy almost the entire gland. Pathological studies in the modern era have refined this information and suggest a prevalence rate of approximately $14.4 \%$ [3], although most of these are small $(<2 \mathrm{~mm}$ diameter) and macroadenomas are rarely identified incidentally on autopsy [4].

\section{"...pituitary adenomas do not always present in the same way and may be noted by chance during the investigation of other problems."}

However, for the clinical endocrinologist and epidemiologist, pituitary adenomas present in a very different, real-life setting. While for many years clinically relevant pituitary adenomas were thought to be something of a rarity, more recent cross-sectional population studies have altered this view. In a study in the province of Liège, Belgium, we found that proven pituitary adenomas with clinical signs/symptoms occurred with a prevalence of approximately one in 1000 of the general population [5], a rate that has also been largely replicated in the UK [6]. While these tumors presented classically with clinical correlates of hormonal abnormalities, pituitary adenomas do not always present in the same way and may be noted by chance during the investigation of other problems.

The use of computed tomography (CT) and MRI has exploded over the last two decades, largely due to increased deployment of equipment in developed nations $[7,101]$. Indeed the latest international statistics indicate that there are now on average 11.0 MRI scanners and 22.3 CT scanners per million population among Organization for Economic Cooperation and Development countries [101]. This translates into 41.3 and $110.7 \mathrm{MRI}$ and CT scans performed per 1000 of the population per year, respectively [101]. In particular, neuroimaging of the head occurs very frequently in the emergency room setting, with the latest information showing that almost $7 \%$ of emergency room attendees in the USA receive a CT or MRI scan (most common reasons: trauma, headache and dizziness) [7,8]. Given that there are more than 117 million emergency room visits per annum in the USA, this indicates that a huge amount of acute neuroimaging of 
the head occurs annually [8]. Against this background, the importance of pituitary tumors discovered incidentally on CT/MRI scans for other causes becomes very apparent. Data from metaanalyses suggest that pituitary adenomas are present in over $22 \%$ of head CT/MRI scans [3]. Again, while many of these tumors are small, macroadenomas can be discovered incidentally in patients without suspected pituitary disease [9].

The discovery of a pituitary adenoma as an incidental finding on CT/MRI presents a number of challenges. First, the patient will be concerned about this finding and will seek information about what this means and what it implies. Such questions cannot be answered easily in the first instance based on a scan alone. The endocrinologist, on receiving the referral, must initially backtrack to determine whether any clinical symptoms or signs are present. Similarly, the issue of hormonal abnormalities needs to be explained to the patient and relevant testing planned. However, the appropriate follow-up needs to take into account initial clinical findings and balance these against avoiding unnecessary overinvestigation of patients whose pituitary tumors are not likely to represent an immediate clinical challenge. Similarly, the temptation to pass off incidentalomas as clinically irrelevant has to be avoided, as this can miss the opportunity to undertake necessary interventions to improve or preserve the patient's health.

Optimal management of pituitary incidentalomas has been an open question for many years due to the lack of an agreed framework for investigation and follow-up. Thankfully, clinicians now have a new reference point with the publication of 'Pituitary Incidentaloma: An Endocrine Society Clinical Practice Guideline' [1]. This evidence-based document (co-sponsored by the European Society of Endocrinology) used the Grades of Recommendation Assessment, Development and Evaluation (GRADE) system to describe the quality of the evidence and the strength of the recommendations made regarding evaluation, initial testing, therapy and follow-up testing of patients presenting with a pituitary incidentaloma. Importantly, the guideline document is accompanied by a patient information section to help explain the nature of incidentally discovered pituitary adenomas and their management [10].

It is practically useful to outline the recommendations from the beginning, at the initial referral of the patient. First, the patient presenting with a pituitary incidentaloma should have a history and physical examination, including a specific search for indications of hyper- and hypopituitarism. On a separate note, the initial clinical evaluation is also an ideal setting to enquire about family history in order to identify possible cases of multiple endocrine neoplasia 1 and newer conditions, such as familial isolated pituitary adenomas [11]. All patients with a pituitary incidentaloma should undergo clinical and laboratory assessments for hormonal hypersecretion and hyposecretion. At the initial visit, evaluation for hypersecretion should assess for prolactin, IGF-1 and cortisol (and/or adrenocorticotropic hormone), although the choice of laboratory testing can be guided to some extent by clinical examination findings. For patients with small microadenomas ( $5 \mathrm{~mm}$ or less in diameter), routine screening for biochemical evidence of hypopituitarism is not felt to be mandatory, as lesions of this size are rarely associated with pituitary hypofunction. For larger microadenomas and all macroadenomas, the symptoms and clinical examination can guide hormonal testing choices, with particular attention needed regarding the challenges of accurately diagnosing growth hormone deficiency. In terms of mass effects, the guidelines recommend that all patients presenting with a pituitary incidentaloma that is abutting the optic nerves/chiasma on MRI have a formal visual field exam. This should be performed even if patients do not report visual symptoms, as unrecognized abnormalities have been reported in $5-15 \%$ of cases. A practical point is that patients with an incidentaloma that is diagnosed on CT scan should ideally have an MRI (with fine cuts through the sella and with and without gadolinium if renal function allows) in order to more precisely appreciate the size of the tumor and its relations to adjacent structures.

\section{“...appropriate follow-up needs to take into account initial clinical findings and balance these against avoiding unnecessary over-investigation of patients whose pituitary tumors are not likely to represent an immediate clinical challenge."}

Once the incidentaloma has undergone initial investigation, patients who do not meet criteria for surgery should be followedup with clinical assessments and nonsurgical therapy as required. Practically, the removal of an asymptomatic pituitary incidentaloma that has no associated hormonal abnormalities or physical compressive effects is not warranted. The conservative approach for this form of follow-up remains to be fully defined as, to date, evidence in the literature is scanty. However, the following recommendations can be made for investigations in addition to clinical assessments: a 6-monthly MRI for macroincidentalomas and 12-monthly MRI for microincidentalomas. Thereafter, if no size increase is seen, macroincidentalomas should have an MRI every 12 months and microincidentalomas every $1-2$ years. If the adenoma is seen to be stable for 3 years, then MRI can be undertaken more infrequently, although clinical examinations should be continued. Patients with macroincidentalomas should undergo hormonal testing for hypopituitarism 6 months after initial testing and then 12-monthly thereafter (microadenomas are less likely to cause hypopituitarism without an increase in size on MRI). Patients who develop new clinical signs and symptoms or increases in size on MRI should undergo testing as appropriate for hormonal abnormalities. For patients with tumor size increases on MRI that newly touch or compress the optic nerves/chiasma, visual fields should be retested.

Patients with incidentalomas should be referred for surgery if they have a visual field defect caused by the pituitary tumor, other visual abnormalities caused by the tumor, a tumor that abuts or compresses the optic nerves for chiasma on MRI, pituitary apoplexy or hormonal hypersecretion (except prolactinoma). In all cases, appropriate guidelines for the management of hypersecreting pituitary tumors should be followed. Patients who have the following criteria should be also considered for 
surgery: growth of the incidentaloma, loss of hormonal function, patients considering pregnancy who have a tumor close to the optic chiasma and patients with unrelenting headache.

The guideline document itself contains further discussion of all of these points and should be considered in full in order to tailor the recommendations to the needs of each and every patient individually. Owing to the common occurrence of pituitary tumors in the population and the likely expanded use of MRI and $\mathrm{CT}$ of the head in the emergency setting or for investigation of nonendocrine conditions, the challenges of how to manage the patient with a pituitary incidentaloma are likely to remain an everyday problem for the pituitary specialist. Hopefully, as prospective studies provide more information on the natural history of pituitary incidentalomas and their evolution, the recommendations in this guideline can be further refined and adapted to improve patient outcomes.

\section{Financial \& competing interests disclosure}

The authors have no relevant affiliations or financial involvement with any organization or entity with a financial interest in or financial conflict with the subject matter or materials discussed in the manuscript. This includes employment, consultancies, honoraria, stock ownership or options, expert testimony, grants or patents received or pending, or royalties.

No writing assistance was utilized in the production of this manuscript.

\section{References}

1 Freda PU, Beckers AM, Katznelson L et al. Pituitary incidentaloma: an endocrine society clinical practice guideline. J. Clin. Endocrinol. Metab. 96(4), 894-904 (2011).

2 Costello RT. Subclinical adenoma of the pituitary gland. Am. J. Pathol. 12(2), 205-216 (1936).

3 Ezzat S, Asa SL, Couldwell WT et al. The prevalence of pituitary adenomas: a systematic review. Cancer 101(3), 613-619 (2004).

4 Buurman H, Saeger W. Subclinical adenomas in postmortem pituitaries: classification and correlations to clinical data. Eur. J. Endocrinol. 154(5), 753-758 (2006).

5 Daly AF, Rixhon M, Adam C, Dempegioti A, Tichomirowa MA, Beckers A. High prevalence of pituitary adenomas: a cross-sectional study in the province of Liege, Belgium. J. Clin. Endocrinol. Metab. 91(12), 4769-4775 (2006).

6 Fernandez A, Karavitaki N, Wass JA. Prevalence of pituitary adenomas: a community-based, cross-sectional study in Banbury (Oxfordshire, UK). Clin. Endocrinol. 72(3), 377-382 (2010).

7 Tabas JA, Hsia RY. Invited commentary - emergency department neuroimaging: are we using our heads? Comment on "Use of neuroimaging in US emergency departments". Arch. Intern. Med. 171(3), 262-264 (2011).

8 Raja AS, Andruchow J, Zane R, Khorasani R, Schuur JD. Use of neuroimaging in US emergency departments. Arch. Intern. Med. 171(3), 260-262 (2011).
9 Vernooij MW, Ikram MA, Tanghe HL et al. Incidental findings on brain MRI in the general population. N. Engl. J. Med. 357(18), 1821-1828 (2007).

10 Freda P, Katznelson L, Molitch M. Patient guide to pituitary incidentaloma assessment and treatment. J. Clin. Endocrinol. Metab. 96(4), 35A-36A (2011).

11 Jaffrain Rea ML, Daly AF, Angelini M, Petrossians P, Bours V, Beckers A. Genetic susceptibility in pituitary adenomas: from pathogenesis to clinical implications. Expert Rev. Endocrinol. Metab. 2, 195-214 (2011).

\section{Website}

101 OECD. Medical technologies: CT scanners and MRI units. In: OECD Health at a Glance: Europe 2010. OECD Publishing (2010) www.oecd.org/health/healthataglance/ europe 
